\title{
Respiratory tract disease in systemic lupus erythematosus
}

\author{
J C DE JONGSTE, H J NEIJENS, E J DUIVERMAN, J M BOGAARD, AND \\ K F KERREBIJN
}

Departments of Paediatrics and Respiratory Diseases, Erasmus University and University Hospital Rotterdam/Sophia Children's Hospital, Rotterdam, The Netherlands

SUMMARY Respiratory tract involvement is common in adults with systemic lupus erythematosus (SLE). Although SLE in children usually follows a more severe course than in adults, there are few reports on pulmonary disease and lung function in children with SLE. We performed lung function tests and chest $x$ ray examinations in eight children with SLE (mean age 11.1 years), three of whom presented with pulmonary symptoms. A high prevalence of lung involvement was found, including interstitial or localised infiltrations, pleural effusion, a restrictive impairment of lung function, and dysfunction of the diaphragm. Three patients required artificial ventilation. Two main mechanisms of ventilatory impairment seem to occur in children with SLE: firstly, acute interstitial pneumonia, which rapidly improves on treatment with steroids, and, secondly, restriction of lung volume, mainly due to respiratory muscle weakness.

Systemic lupus erythematosus (SLE) is characterised by the production of auto-antibodies that damage multiple organ systems. Respiratory tract abnormalities are frequently observed in adult patients with SLE. The most common findings are sterile pleural effusion and pneumonia, which is usually due to infection. ${ }^{1-7}$ Interstitial lung disease is found in only $3 \%$ of adult patients with SLE. ${ }^{1}$ Lung function studies in adults, however, have revealed a high incidence of abnormalities even in the absence of clinically apparent lung disease. ${ }^{2}$ Volume restriction, decreased compliance, reduced diffusion capacity, and hyperventilation with arterial hypoxia at rest or during exercise have been reported. ${ }^{2-6}$ In adult patients with SLE the degree of lung function impairment correlated poorly with clinical and $x$ ray findings. ${ }^{4}$ Lung function seemed to be the most sensitive indicator of pulmonary involvement. ${ }^{4}$ SLE is uncommon in children aged 15 years or younger. When SLE does occur in this age group it often seems to follow a more severe course than in adults. ${ }^{78}$ Pleural and pulmonary involvement have been reported in up to $70 \%$ of paediatric patients with SLE, pleural effusion being the most common finding. ${ }^{9-11}$ There are few data on lung function in children with SLE: Singsen and Platzker found restrictive defects in seven $(35 \%)$ and diffusion impairment in five $(25 \%)$ of 20 patients with SLE (mean age 15.5 years) without clinical or radiological evidence of pulmonary disease. ${ }^{11}$

We have diagnosed SLE in eight children aged 6-14 years in the Sophia Children's Hospital since 1980. In some of these patients pulmonary involvement was a prominent feature early in the course of the disease. We therefore examined all the cases for the presence and extent of respiratory tract involvement. Four patients were followed for two to three years.

\section{Methods}

SLE was diagnosed according to the criteria published by the American Rheumatism Association. ${ }^{12}$ These criteria were fulfilled by four girls and four boys aged 6-14 years, who were referred to the Sophia Children's Hospital between 1980 and 1985 because of multisystem disease. Treatment with steroids (prednisolone $60 \mathrm{mg} / \mathrm{m}^{2}$ per day in three divided doses) was begun in all patients when the diagnosis of SLE had been confirmed.

Evaluation of respiratory tract involvement included physical examination, chest $x$ ray examinations (anteroposterior inspiration and expiration and right transverse views), and lung function studies. Lung function was measured for the first time as soon as permitted by the clinical condition of 
the patients and, in two cases who came to our attention later, two and three years after diagnosis. Lung volumes were determined with a water locked spirometer (Mijnhardt), and total lung capacity was measured with the helium dilution method. Flowvolume curves were obtained using a Fleisch heated pneumotachograph. To determine if airway obstruction was present together with volume reduction, the maximal expiratory flows were normalised for total lung capacity, ${ }^{13}$ and the shape of the flowvolume loops was examined qualitatively. In all patients lung function was measured before and after bronchodilatation (fenoterol $0.4 \mathrm{mg}$ administered by metered dose inhaler). Expiratory semistatic compliance measurements were performed according to the technique described by Zapletal et al. ${ }^{14}$ The diffusion capacity for carbon monoxide $\left(\mathrm{D}_{\mathrm{CO}}\right)$ was measured with a single breath technique, ${ }^{15}$ except in case 2 where accurate measurement was not possible because of a severe restriction of her vital capacity. The transdiaphragmatic pressure gradient was measured as the difference in oesophageal and gastric pressures during a maximal inspiratory effort against a closed valve at $0 \%$ and $30 \%$ of vital capacity, as described by Vanmeenen et al. ${ }^{16}$

We used the reference values of Zapletal et al for lung volumes and compliance, ${ }^{1+17}$ of Michaelson et al for flows corrected for total lung capacity, ${ }^{13}$ and of Vanmeenen et al for transdiaphragmatic pressures. ${ }^{16}$ Our own measurements in healthy school children aged 10 to 20 years were used as a

Table 1 Clinical and laboratory data* of the eight children with systemic lupus erythematosus

\begin{tabular}{|c|c|c|c|c|c|c|c|c|}
\hline & \multicolumn{8}{|c|}{ Case No } \\
\hline & $I$ & 2 & 3 & 4 & 5 & 6 & 7 & 8 \\
\hline Age (years) & 6 & 9 & 10 & 12 & 12 & 1.3 & 13 & 14 \\
\hline Sex & $\mathrm{F}$ & $\mathrm{F}$ & $\mathrm{F}$ & $\mathbf{M}$ & M & M & $\mathbf{M}$ & $\mathrm{F}$ \\
\hline Weight loss & + & + & + & - & + & + & - & + \\
\hline Fever & + & + & + & - & + & - & - & + \\
\hline Arthritis/arthralgia/myalgia & + & + & + & + & + & + & + & + \\
\hline \multicolumn{9}{|l|}{ Heart: } \\
\hline Cardiomegaly & + & + & - & + & + & - & - & + \\
\hline Pericardial effusion & + & + & - & + & - & - & - & + \\
\hline Conduction defect & + & + & + & + & + & - & - & - \\
\hline Cardiac failure & + & - & - & + & - & - & - & - \\
\hline Hypertension & + & + & - & + & + & - & - & - \\
\hline \multicolumn{9}{|l|}{ Lungs: } \\
\hline Pleurisy & + & + & - & + & + & + & - & + \\
\hline Pulmonary infiltrates & + & + & + & - & - & - & - & + \\
\hline - Respiratory insufficiency & + & - & - & + & - & - & - & + \\
\hline \multicolumn{9}{|l|}{ Skin and mucous membranes: } \\
\hline Butterfly rash & - & + & - & - & + & + & - & - \\
\hline Exanthema & + & + & + & - & + & + & - & - \\
\hline Purpura & + & - & - & + & - & - & - & + \\
\hline Subcutaneous fat necrosis & - & + & - & - & - & - & - & - \\
\hline Mucous membrane lesions & + & - & - & - & + & - & - & - \\
\hline \multicolumn{9}{|l|}{ Nervous system: } \\
\hline Convulsions & - & + & - & + & - & - & - & - \\
\hline Central nervous system damage (paresis etc) & + & - & + & - & - & - & - & - \\
\hline Psychosis & - & - & - & + & - & - & - & - \\
\hline \multicolumn{9}{|l|}{ Kidncys: } \\
\hline Nephritis & + & + & + & + & + & + & + & + \\
\hline Renal insufficiency & + & - & - & + & - & + & - & - \\
\hline \multicolumn{9}{|l|}{ Gastrointestinal: } \\
\hline Enteritis & + & - & - & - & - & - & - & - \\
\hline Haemorrhage & + & - & + & - & - & - & - & - \\
\hline Lymphadenopathy. splenomegaly. hepatomegaly & + & - & + & - & - & - & - & - \\
\hline \multicolumn{9}{|l|}{ Blood: } \\
\hline Anatmia (Coombs test positive) & + & + & + & + & + & - & - & - \\
\hline Lymphocytopenia & - & + & + & + & + & - & - & - \\
\hline Thrombocytopenia & + & + & + & + & - & + & - & + \\
\hline Raised erythrocyte sedimentation rate & + & + & + & - & + & + & + & + \\
\hline
\end{tabular}

*At any time during the course of the discase. 
reference for $\mathrm{D}_{\mathrm{CO}}$ values (H Stam. Unpublished observations).

\section{Results}

The presenting symptoms were pulmonary shadows (cases 2, 6, and 8), with respiratory insufficiency (case 8), nephritis (case 4), arthritis (case 3), and general malaise, fever, and arthralgia (cases 1, 5, and 7).

Clinical and laboratory data are summarised in Table 1. All patients eventually developed nephritis,

Table 2 Results of initial chest $\mathrm{x}$ ray examinations in eight children with systemic lupus erythematosus

\begin{tabular}{|c|c|c|c|c|c|c|c|c|}
\hline & \multicolumn{8}{|c|}{ (ase No } \\
\hline & 1 & 2 & 3 & 4 & 5 & 0 & 7 & 8 \\
\hline Pleural effusion & + & + & - & + & + & + & - & + \\
\hline \multicolumn{9}{|l|}{ Pulmonary shadowing: } \\
\hline Diffuse interstitial & + & + & - & - & - & - & - & + \\
\hline Patchy & + & + & + & - & - & - & - & - \\
\hline Atelectasis & + & + & - & + & - & - & - & - \\
\hline Diaphragm elevation & + & + & + & - & + & - & - & - \\
\hline Atonic chest configuration & + & + & + & - & + & - & - & - \\
\hline
\end{tabular}

and three (cases 1, 4, and 6) progressed to renal insufficiency requiring haemodialysis.

Chest $x$ ray examinations revealed abnormalities in seven patients (Table 2), varying from isolated pleural effusion to interstitial shadowing, pleural effusion, elevation and insufficient excursion of the diaphragm, and narrow intercostal spaces with downward slanting of the ribs (atonic chest) (Fig. 1). Sputum cultures were always negative, except in case 1, where Staphylococcus aureus and Candida albicans were isolated later in the course of the disease. We measured lung function in all the patients except case 1. Artificial ventilation was necessary until this patient died. Ventilator settings indicated that compliance and diffusion capacity were highly abnormal.

The results of lung function measurements are shown in Table 3. Spirometric data showed a severe restriction in four patients, mainly due to a reduced inspiratory reserve volume. The forced expiratory volume in one second:forced vital capacity ratio, expiratory flows corrected for total lung capacity, and the patterns of the flow-volume curves were normal. No changes were observed after administration of fenoterol.

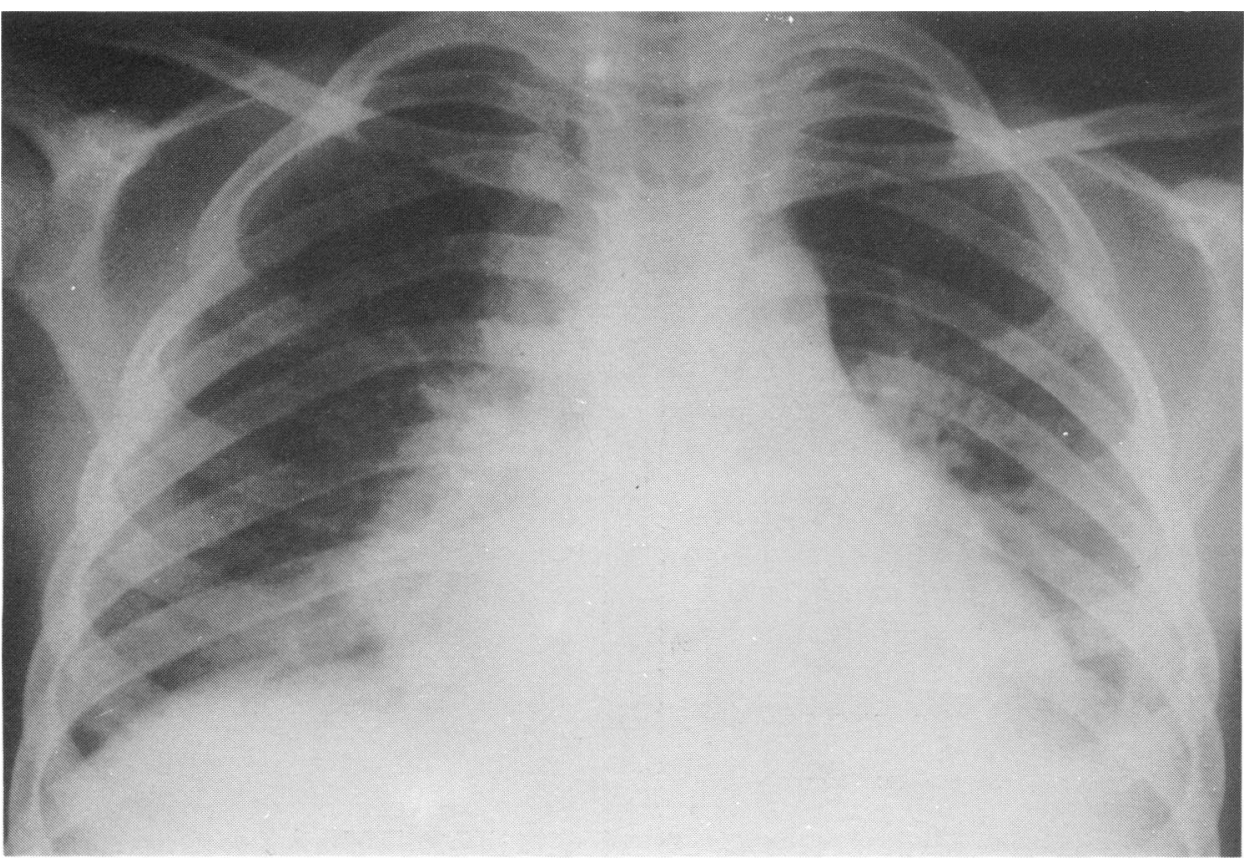

Fig. 1 Chest $\mathrm{x}$ ray of case 1 made shortly after admission, showing diffuse interstitial shadowing of both lower lung fields, pleural effusion on the left side, enlargement of the heart and hilar structures, broadening of the superior mediastinum, atonic configuration of the chest (narrow intercostal spaces, downward slanting of the ribs in inspiration), and elevation of the diaphragm. 
Table 3 Results of lung function tests in seven children with systemic lupus erythematosus, measured at first presentation

\begin{tabular}{|c|c|c|c|c|c|c|c|c|}
\hline & & \multicolumn{7}{|c|}{ Case No } \\
\hline & & 7 & 8 & 6 & 4 & $3^{*}$ & 5 & $2+$ \\
\hline TLC & (\% predicted) & 102 & 89 & 82 & 68 & 65 & $60)$ & 37 \\
\hline IRV & (\% TLC) & 37 & 46 & 42 & 57 & 38 & 34 & 18 \\
\hline TV & (\% TLC) & 7 & 9 & 14 & 11 & 16 & 20) & 25 \\
\hline ERV & (\% TLC) & 31 & 18 & 18 & 13 & 24 & 21 & 13 \\
\hline RV & (\% TLC) & 25 & 27 & 26 & 19 & 22 & 25 & 44 \\
\hline FVC & (\% predicted) & 101 & 85 & 74 & 75 & 70 & 59 & 33 \\
\hline FEV & (\% FVC) & 90 & 90 & 85 & 80 & 84 & 96 & 84 \\
\hline $\mathrm{MEF}_{50} \% \mathrm{FVC}$ & (\% predicted) & 135 & 86 & 73 & 64 & 92 & 89 & 34 \\
\hline MEF $_{5() \% F V C} /$ TLC & (\% predicted) & 124 & 96 & 118 & 82 & 141 & 143 & 80 \\
\hline $\mathrm{MEF}_{25 \%+\mathrm{FC}}$ & (\% predicted) & 110 & 79 & 53 & 58 & 68 & 91 & 23 \\
\hline $\mathrm{MEF}_{25 \% \mathrm{FV}} / \mathrm{TLC}$ & (\% predicted) & 94 & 82 & 57 & 68 & 155 & 127 & 59 \\
\hline $\mathrm{C}_{1 . \mathrm{st}} \% \mathrm{TLC} / \mathrm{cm} \mathrm{H} \mathrm{H}_{2} \mathrm{O}$ & (\% predicted) & 94 & 87 & 77 & 115 & - & 76 & 63 \\
\hline $\mathrm{D}_{\mathrm{CO}} / \mathrm{BSA}$ & (\% predicted) & 87 & 65 & 55 & 80 & 58 & 69 & - \\
\hline $\mathrm{D}_{\mathrm{CO}} / \mathrm{TLC}$ & (\% predicted) & 96 & 81 & 107 & 97 & 113 & 125 & - \\
\hline
\end{tabular}

* Measured three years after diagnosis.

tMeasured two years after diagnosis.

Abbreviations: TLC=total lung capacity; IRV=inspiratory reserve volume; $T V=$ tidal volume; ERV=expiratory reserve volume; $R V=$ residual volume; $F V C=$ forced vital capacity; $\mathrm{FEV}_{1}=$ forced expiratory volume in one second; $\mathrm{MEF}_{501-25 \% \mathrm{FVC}}=$ maximal expiratory flow after $50-75 \%$ of the $\mathrm{FVC}$ is expired;

$\mathrm{C}_{1, \mathrm{st}}=$ semistatic compliance; $\mathrm{D}_{\mathrm{CO}}=$ carbon monoxide diffusion capacity; $\mathrm{BSA}=$ body surface area.

Semistatic compliance measurements were abnormal in three patients (below $80 \%$ predicted). In all six subjects in whom it was measured $\mathrm{D}_{\mathrm{CO}}$ was diminished for body surface area but normal or increased for the remaining lung volume. In two subjects with a restriction in lung capacity (cases 2 and 5) and one with normal lung function at that time (case 8) we measured transdiaphragmatic pressures at $0 \%$ and $30 \%$ of vital capacity (Fig. 2). During a maximal inspiratory effort against a closed valve, decreased transdiaphragmatic pressure gradi-

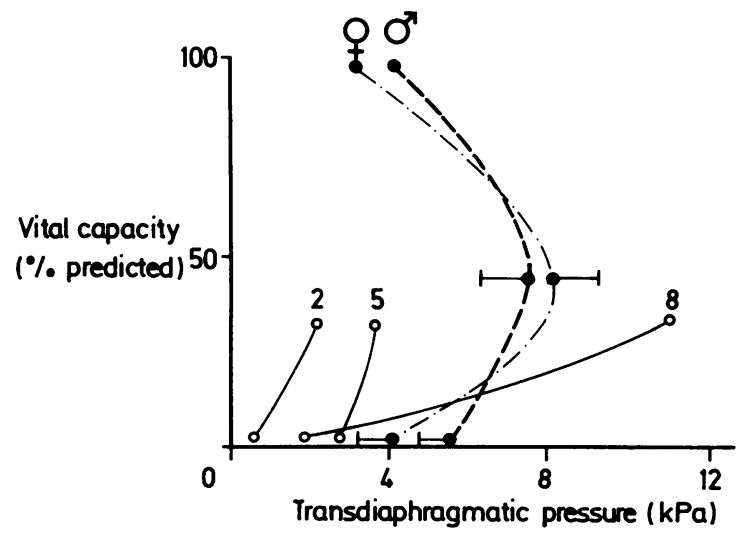

Fig. 2 Results of transdiaphragmatic pressure measurements in cases 2, 5, and 8. The gradient between transpleural and intra-abdominal pressures during maximal inspiratory efforts against a closed valve at $0 \%$ and $30 \%$ of vital capacity are shown. Reference values, shown by broken lines, are from the paper by Vanmeenen et al. ${ }^{16}$ ents were found in cases 2 and 5 and normal values in case 8. Conventional electromyographic studies were performed in cases 2 and 4 and indicated the presence of myopathy.

In four patients we had the opportunity to repeat lung function measurements at roughly half yearly intervals (Fig. 3). Most subjects had one or more relapses of SLE after tapering the treatment with steroids. Six patients were eventually given azathioprine $(2-4 \mathrm{mg} / \mathrm{kg} /$ day $)$ because of steroid toxicity or frequent relapses with progression to renal insufficiency. Three patients showed a gradual improvement in vital capacity over several years, which was unaffected by changes in the activity of

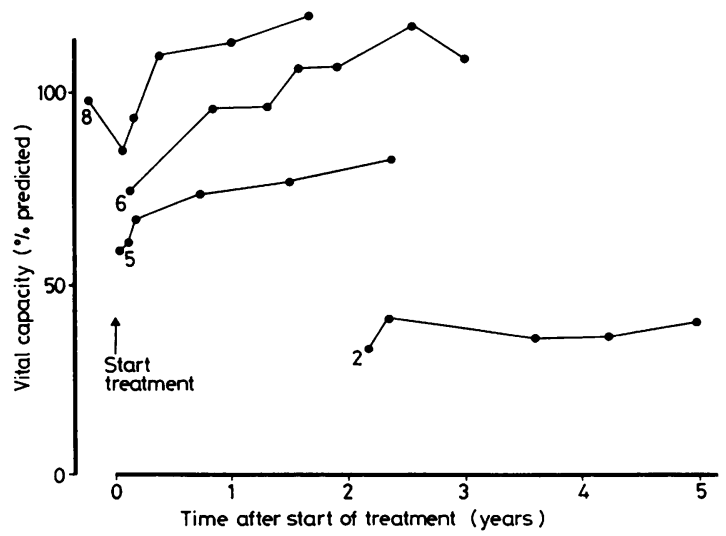

Fig. 3 Follow up data of vital capacity measurements in four children with systemic lupus erythematosus (cases 2, 5 , 6 , and 8). 
SLE. A stable restriction was present in case 2, which was not influenced by SLE relapses. In case 8 we measured lung function before SLE was diagnosed. She was initially referred because of fatigue and had no other symptoms suggestive of SLE. At that time no abnormalities in lung function were detected. A few months later she developed the acute severe interstitial pneumonia that led to the diagnosis of SLE. She required artificial ventilation for two weeks and improved dramatically after the beginning of treatment with steroids. One week after the artificial ventilation was stopped the lung function measurements were repeated and indicated a mild restriction, which improved slowly in the following years (Fig. 3).

Blood gases, determined in arterialised capillary blood samples, were normal in all the patients except during acute episodes of respiratory insufficiency in cases 1,4 , and 8 . Case 1 developed a progressive interstitial pneumonia and needed artificial ventilation with high airway pressures and oxygen for one month. She then died due to massive gastrointestinal blood loss. Autopsy showed a widespread necrotising vasculitis affecting all organ systems. The lungs showed interstitial inflammation and a diffuse haemorrhagic tracheobronchitis. Case 4 , who was on haemodialysis, required ventilatory support several times because of acute pulmonary oedema. This was probably due to fluid overload. This patient died three years after diagnosis from pulmonary oedema, seizures, and cardiac arrythmia.

\section{Discussion}

Our findings suggest a high prevalence of lung disease in childhood SLE. The most common findings were pleural effusion and volume restriction; three of our patients presented with severe respiratory symptoms.

Interstitial lung disease, which is infrequently seen in adults with SLE, ${ }^{1}$ was present on $x$ ray examination in three and was histologically confirmed in one of our eight patients. Treatment with steroids seemed to be clinically effective in two of these subjects (cases 2 and 8 ). The normal diffusion capacity when corrected for lung volume in case 8 suggested that no important interstitial disease had remained. A considerable restriction of vital capacity persisted, however, in case 2 and was also found in three patients without radiological signs of interstitial disease and normal diffusion capacity (cases 4, 5, and 6). Martens et al found normal or only slightly lowered $\mathrm{D}_{\mathrm{CO}}$ /total lung capacity values in seven adult patients with SLE with a restriction in lung volume. ${ }^{18}$ These findings suggest that this restriction is not only due to interstitial lung disease but that other abnormalities may be present as well.

Dysfunction of the diaphragm and other respiratory muscles in adult patients with SLE, which may be due to myopathy, has been reported recently. ${ }^{18-20}$ We found markedly decreased transdiaphragmatic pressures in two patients who had restriction in lung volumes (cases 2 and 5). One of these patients (case 2) had clinical and electromyographic signs of myopathy in other muscles. This suggests that the respiratory muscle strength was impaired due to myopathy. The decreased compliance in three patients, two of whom had no radiological signs of interstitial lung disease, might have been caused mainly by muscle weakness with diminished inflation of normal lung tissue and not by interstitial fibrosis and inflammation. This possibility has been suggested by Martens et al, who found normalisation of the compliance after passive lung inflation to normal volume in adult patients with SLE. ${ }^{18}$ For technical reasons, this could not be performed in our patients. Multiple small atelectases, which have been described in lungs from adult patients with SLE, might also have contributed to an increased lung stiffness and a restriction in lung volume. Maximal expiratory flows were low in four patients. Normal values were obtained, however, after correction for total lung capacity. Together with the normal shape of the flow-volume loops, this makes airway obstruction unlikely.

Localised pulmonary shadows were present in three patients. Although we cannot exclude that this may have been due to infection, this seems unlikely because initially no micro-organisms were cultured from the sputum, which was usually scanty and clear. Furthermore, treatment with antibiotics was always ineffective, and these pulmonary shadows resolved during treatment with steroids. Secondary infection was only documented in case 1 , who deteriorated despite maximal therapeutic efforts.

The severity of lung disease was not related to the overall activity of the disease. Several patients experienced relapses and, for instance, developed rapidly progressive glomerulonephritis without a decrease in lung function. Furthermore, in three of the four patients we followed the lung function improved gradually regardless of SLE relapses. This contrasts with the course of the renal disease in SLE, which tends to progress to renal failure despite treatment.

In conclusion, we have found a high prevalence of disease of the respiratory tract in childhood SLE. Our findings suggest that there are two main reasons for the impairment in lung function in these children. The first is interstitial pneumonia, which follows an acute course and improves on treatment 
with steroids. The second is respiratory muscle weakness, which is not particularly disabling and can persist for years.

The authors thank Dr E D Wolff, Dr R N Sukhai, and Dr A J van der Heijden, paediatric nephrologists, who allowed us to study their patients, and $\operatorname{Dr} M$ Meradji, paediatric radiologist, for his expert comments.

\section{References}

' Dubois EL. The clinical picture of systemic lupus erythematosus. In: Dubois EL. ed. Lupus erythematosus. 2nd ed. Los Angeles: University of Southern California Press, 1974:385-97.

2 Arnalich F, Ruiz de Andrés S, Gil A, Puig JG, Barbado J. Vazquez JJ. Pulmonary function in systemic lupus erythematosus patients without respiratory symptoms. Bull Eur Physiopathol Respir 1979;15:649-57.

3 Gold WM. Jennings DB. Pulmonary function in patients with systemic lupus erythematosus. Am Rev Respir Dis 1966;93: 556-67.

+ Huang CT. Lyons HA. Comparison of pulmonary function in patients with systemic lupus erythematosus, scleroderma and rheumatoid arthritis. Am Rev Respir Dis 1966;93:865-75.

5 Grennan DM. Howic AD, Moran F, Buchanan WW. Pulmonary involvement in systemic lupus erythematosus. Ann Rheum Dis 1978:37:536-9.

' Silberstein SL, Barland P, Grayzel AI, Koerner SK. Pulmonary dysfunction in systemic lupus erythematosus: prevalence, classification and correlation with other organ involvement. J Rheumatol 1980;7:187-95.

7 Meislin AG, Rothfield N. Systemic lupus erythematosus in childhood. Analysis of 42 cases, with comparative data on 200 adult cases followed concurrently. Pediatrics 1968:42:37-49.

* Schaller J. Lupus in childhood. Clin Rheum Dis 1982:8:219-28.

"King KK, Kornreich HK, Bernstein BH, Singsen BH, Hanson $V$. The clinical spectrum of systemic lupus erythematosus in childhood. Arthritis Rheum 1977:20:287-94.

11) Caciro F, Michiclson FMC. Bernstein R. Hughes GRV,
Ansell BM. Systemic lupus erythematosus in childhood. Ann Rheum Dis 1981;40:325-31.

1 Singsen BH, Platzker CG. Pulmonary involvement in the rheumatic disorders of childhood. In: Kendig EL, Chernick V, eds. Disorders of the respiratory tract in children. 4th ed. Philadelphia: WB Saunders, 1983:846-72.

12 Tan EM, Cohen AS, Fries JFEA. The 1982 revised criteria for the classification of systemic lupus erythematosus. Arthritis Rheum 1982;25:1271-7.

1.3 Michaelson ED, Watson H, Silva G, Zapata A, SerafiniMichaelson SM, Sackner MA. Pulmonary function in normal children. Bull Eur Physiopathol Respir 1978;14:525-50.

${ }^{4}$ Zapletal A, Misur M, Samanek M. Static recoil pressure of the lungs in children. Bull Eur Physiopathol Respir 1971;7:139-43.

15 Ogilvie CM, Forster RE, Blakemore WS, Morton JW. A standardized breath holding technique for the clinical measurement of the diffusing capacity of the lung for carbon monoxide. J Clin Invest 1957:36:1-17.

16 Vanmeenen MT, Demedts M, Vaerenberg H, Ghesquiere J. Transdiaphragmatic. esophageal and gastric pressures during maximal static inspiratory and expiratory efforts in young subjects: effects of maneuver and sex. Eur J Respir Dis 1984;65:216-23

17 Zapletal A. Paul T. Samanek M. Normal values of static lung volumes and ventilation in children and adolescents. Cesk Pediatr 1976;31:532-9.

${ }^{18}$ Martens J, Demedts M, Vanmeenen MT, DeQueker J. Respiratory muscle dysfunction in systemic lupus erythematosus. Chest 1983;84:170-5.

${ }^{19}$ Gibson GJ, Edmonds JP, Hughes GRV. Diaphragm function and lung involvement in systemic lupus erythematosus. $\mathrm{Am} \mathrm{J}$ Med 1977:63:926-32.

20) Thompson PJ, Dhillon DP, Ledingham J, Turner-Warwick M. Shrinking lungs, diaphragmatic dysfunction, and systemic lupus erythematosus. Am Rev Respir Dis 1985;132:926-8.

Correspondence to Dr J C de Jongste, Sophia Children's Hospital, PO Box 70029, 3000 LL Rotterdam, The Netherlands.

Received 5 February 1986 